\title{
Liver pathology in rural south-west Cameroon
}

\author{
J. A. Skalsky ${ }^{1}$, H. I. Joller-Jemelka ${ }^{2}$, L. Bianchi ${ }^{3}$ and $\mathbf{M}$. Knoblauch ${ }^{4}{ }^{1}$ Manyemen General Hospital, Cameroon; \\ ${ }^{2}$ Section of Clinical Immunology, Department of Medicine, University Hospital of Zurich, Switzerland; ${ }^{3}$ Department of \\ Pathology, University Hospital of Basle, Switzerland; ${ }^{4}$ Department of Medicine, Männedorf Hospital, Switzerland
}

\begin{abstract}
In a prospective study, 102 hospital patients with liver disease were evaluated in West Cameroon, Africa. Blood donors, pregnant women and patients without liver disease served as controls. A total of 757 individuals were tested for markers of hepatitis A, B, C and D and for immunological markers (autoantibodies, procollagen III, $\alpha$-foetoprotein, CA50 antigen, $\alpha$-1-antitrypsin and antibodies to human immunodeficiency virus types 1 and 2 ). One-third of the liver disease patients had focal lesions on ultrasound examination. Histologically, 20 cases of cirrhosis, 14 cases of chronic hepatitis, 15 hepatocellular carcinomas and 17 cases of acute hepatitis were detected. All hepatic patients and virtually all controls had had a previous hepatitis A virus infection. Over $85 \%$ of adult patients and controls had at least one marker of hepatitis B virus infection. Over $30 \%$ of patients with liver disease had markers of possible hepatitis B virus replication. Antihepatitis $\mathrm{C}$ virus antibody was present in $18 \%$ of hepatic patients and in $6 \%$ of controls. Hepatitis $\mathrm{C}$ virus infection seems to play an important role in the development of chronic liver pathology; $40 \%$ of cirrhotic patients had a combined hepatitis B and $C$ virus infection. Serum autoantibodies were frequently found and were not correlated with the presence of autoimmune liver disease.
\end{abstract}

Keywords: liver disease, hepatitis A, B, C, D, hepatocellular carcinoma, cirrhosis, Cameroon

\section{Introduction}

Data on liver pathology and hepatitis virus serology from rural tropical Africa are scarce. Being impressed by the frequency of liver diseases in patients at the Manyemen General Hospital in the South-West Province of Cameroon, we conducted a prospective study to elucidate the nature, aetiology and diagnostic management of liver disease in hospital patients during a period of 2 years.

The study included a standardized clinical investigation, ultrasound examination, liver function tests, liver histology, hepatitis virus and human immunodeficiency virus (HIV) serology, and the determination of several autoantibodies and immunological markers. Blood donors, pregnant women and patients with minor complaints not related to the liver served as controls.

Manyemen is situated in the rural, tropical forest area of the South-West Province of Cameroon. The Presbyterian General Ilospital at Manyemen has 115 beds and a large primary health care service and serves a population of about 250000 in a area of $15000 \mathrm{~km}^{2}$. Falciparum malaria and filarial infections are hyperendemic, whereas parasites invading the liver, such as Schistosoma mansoni and liver flukes, are rare.

\section{Study design and Methods}

We investigated 102 consecutive patients from September 1990 to August 1992. Inclusion criteria were clinically suspected liver disease on grounds of jaundice, ascites, right upper quadrant pain or a pathological liver mass. Initially 135 patients were enrolled, but 33 had to be excluded because of incomplete data, erroneous diagnosis or pathological conditions not permitting liver biopsy.

For the history, clinical examination and abdominal ultrasound standardized questionnaires and record forms were used. Ultrasound examination was performed using a Siemens Sonoline ${ }^{\circledR} 1300$ linear scanner of $3 \mathrm{MHz}$. Liver biopsy was either performed 'blindly' according to the Menghini technique or under laparoscopic control. The biopsy specimens were kept in $10 \%$ formalin and later examined by one of us (L.B.).

Basic laboratory determinations were performed according to the World Health Organization recommendations (WHO, 1980); liver function tests were performed with the aid of a Boehringer Reflotron-Photometer ${ }^{(8)}$.

For immunological investigations, sera were stored at $-4^{\circ} \mathrm{C}$ and later analysed at the Section of Clinical Immunology of the University Hospital, Zurich, Switzerland.

Address for correspondence: Dr med. J. Skalsky, Unterdorfstrasse 28, CH-8602 Wangen, Switzerland.
Markers of hepatitis A, B, C and D viruses (HAV, HBV, $\mathrm{HCV}$, HDV) and autoantibodies such as anti-nuclear antibodies (ANA), anti-mitochondrial antibodies (AMA), and anti-smooth muscle antibodies (ASM) were determined by indirect immunofluorescence, anti-M2 antibodies (AM2) by an anti-M2 enzyme-linked immunosorbent assay (ELISA) (Elias, Freiburg, Germany), procollagen III by P III-peptide radio-immunoassay (RIA) (Boehring, Marburg, Germany), and $\alpha$-1-antitrypsin with the aid of a BNA-Nephelometer-Analizer ${ }^{\circledR}$ (Boehring, Marburg, Germany). HIV-1 and HIV-2 antibodies were also investigated, using commercial screening test kits and following the procedures recommended by the manufacturers (Abbott Laboratories, North Chicago, Illinois, USA). HIV-1 and HIV-2 antibodies were determined with the Abbott recombinant HIV-1 and HIV-2 enzyme immunoassay. Confirmation was by Western blotting for HIV-1 (Du Pont, USA) and HIV-2 (Pasteur, France). Anti-HCV was measured by a second generation ELISA (Ortho Diagnostic), positive results being confirmed by the Chiryon recombinant immunoblot assay second generation IICV test (Chiryon Corporation, USA).

\section{Results}

The 102 patients with liver disease consisted of 67 males and 35 females, age range 6 months to 80 years (mean $40.5 \pm 19$ years); 64 of 95 gave a history of regular alcohol intake (mainly industrial beers and local palm wine), 7 of 64 reported a blood transfusion, 24 of 60 reported a previous episode of jaundice, and 41 of $53 \mathrm{had}$ taken traditional herbal medicines.

\section{Clincial presentation}

The 5 most frequently encountered clinical presentations among 102 patients were jaundice (related to liver disease), 31 ; right upper quadrant pains, 20 ; ascites, 17 ; right upper quadrant tumour, 16; and hepatomegaly, 15.

\section{Abdominal ultrasound examination}

Focal lesions such as abscesses, tumors or metastases were found in 34 of the 98 patients examined. Sterile, chocolate-coloured pus could be aspirated in 5 instances. Differentiation between amoebic liver abscess, hepatocellular carcinoma (HCC) and malignant lymphoma or metastases was difficult. Puncture and aspiration with a $0.9 \mathrm{~mm} \times 70 \mathrm{~mm}$ Luer needle was safe and helpful in these cases; no complication occurred.

\section{Liver function tests}

Liver function tests were performed on 93 patients 
with liver disease. $\gamma$-Glutamyltransferase ( $\gamma$-glutamyltranspeptidase, EC 2.3.2.2) was elevated in $67 \%$, aspartate aminotransferase (glutamic-oxalacetic transaminase, EC 2.6.1.1) in 57\% and alanine aminotransferase (glutamic-pyruvic transaminase, EC 2.6.1.2) in 45\%.

Bleeding and coagulation times, determined by the Duke/Lee and White methods (WHO, 1980) were normal in all except 3 patients, in whom there was no histological proof of severe, diffuse liver disease.

\section{Histology}

Histological diagnoses were made for 98 patients (Table 1). Of the 20 patients with liver cirrhosis, 8 had a

Table 1. Histological diagnoses for 98 hospital patients in Cameroon

\begin{tabular}{lr}
\hline Liver cirrhosis & 20 \\
Macronodular & 3 \\
Micronodular & 5 \\
Unspecified & 12 \\
Acute hepatitis & 17 \\
Viral & 2 \\
Unspecified & 2 \\
Non-specific reactive & 11 \\
Special forms (giant cell) & 2 \\
Hepatocellular carcinoma & 15 \\
Chronic hepatitis & 14 \\
Chronic active hepatitis & 7 \\
Chronic persistent hepatitis & 3 \\
Granulomatous hepatitis & 4 \\
Secondary biliary inflammation & 9 \\
Liver fibrosis & 8 \\
Amoebic liver abscess & 7 \\
Alcoholic liver disease & 6 \\
Tropical splenomegaly syndrome & 6 \\
Others & 14 \\
Burkitt's lymphoma & 3 \\
Metastatic liver disease (adenocarcinoma) & 2 \\
Haemosiderosis & 2 \\
Liver anomalies (Caroli syndrome, cysts) & 2 \\
Fatty liver & 2 \\
Inconclusive histological diagnosis & 2 \\
HELLP syndrome (combined diagnosis) & 1 \\
\hline Occaionall 2 dagn
\end{tabular}

${ }^{a}$ Occasionally 2 diagnoses were recorded for one patient.

Steatosis as the main histological finding.

concomitant HCC, and 7 patients had HCC in a non-cirrhotic liver. There was a positive correlation between concomitant cirrhosis and $\mathrm{HCC}\left(\chi^{2}=11.82 ; P=0.00059\right)$ (Table 2). Malaria pigment was seen in nearly all the histological specimens.

Table 2. Association between hepatocellular carcinoma and liver cirrhosis

Hepatocellular carcinoma No. of patients Present Absent

\begin{tabular}{llrl}
\hline Liver cirrhosis & & & \\
Present & 20 & 8 & 12 \\
Absent & 78 & 7 & 71 \\
Total & 98 & 15 & 83 \\
\hline
\end{tabular}

Serological markers of viral hepatitis and HIV

The results are summarized in Table 3 and the Figure. All patients with liver discase and virtually all controls had had a previous infection with HAV; $25 \%$ of the healthy children up to 1 year old, and $90 \%$ of those up to 15 years old, who were tested, had anti-HAV antibodies. About $90 \%$ of all the liver disease patients, blood donors and pregnant women had a marker of HBV infection.

Significantly more pregnant women and blood donors were positive for anti-hepatitis B surface antigen anti-
Table 3. Prevalence of serum markers of viral hepatitis, HIV and syphilis in different populations

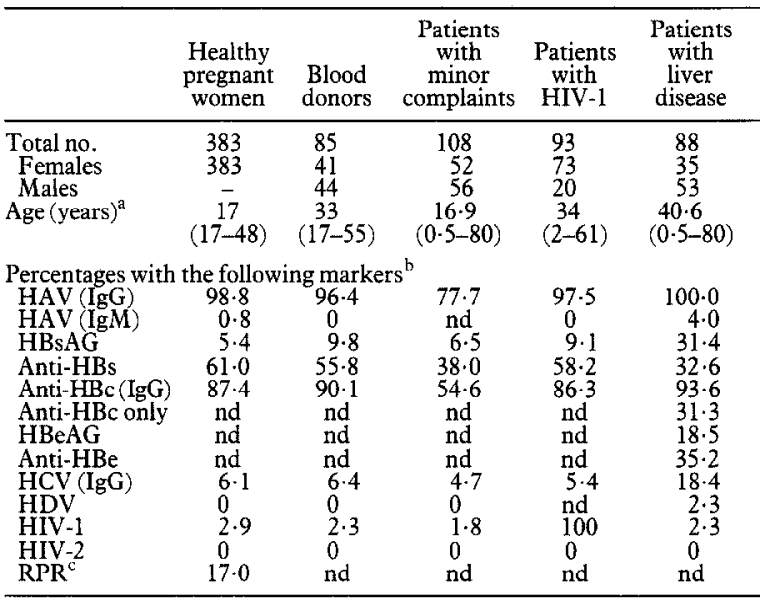

Mean (range in parentheses)

Rapid plasma reagin test for syphilis; other abbreviations re defined in the text.

body (anti-HBs) than patients, the converse being true for the antigen itself ( $\mathrm{HBsAg})$. About $10 \%$ of children up to 5 years old were anti-HBs positive, as were about $40 \%$ of those aged 15 years. The corresponding figures for anti-hepatitis B core antigen (anti-HBc) immunoglobulin $\mathrm{G}$ (IgG) were even higher, $30 \%$ and $57 \%$ respectively.

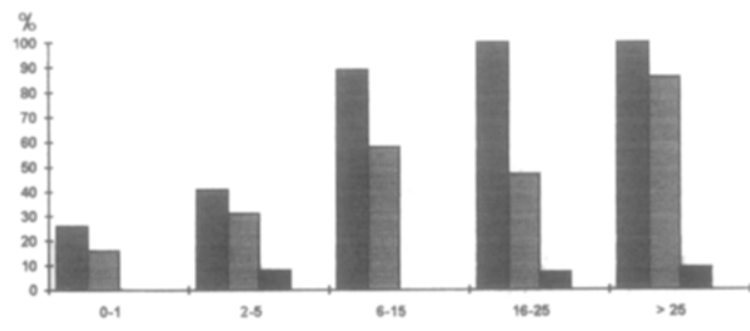

Age group (years)

Figure. Age distribution of hepatitis markers in hospital patients with minor complaints unrelated to liver disease, Cameroon, 1990-1992. Dark grey bars: anti-hepatitis A IgG; light grey bars: anti-hepatitis B core antigen IgG; black bars: anti-hepatitis C IgG.

Among patients with liver disease, markers of possible HBV replication were positive in a high proportion: $\mathrm{HbsAg}$ in $31 \%$, hepatitis B e-antigen (HBeAg) in $18 \%$, and anti-HBc (alone) in 31\%.

Anti-HDV was found in only $2 \%$ of patients with liver disease, but anti-HCV was significantly more common in such patients than in controls $(18 \%$ versus $6 \%$; $P<0.025)$. Because of the inclusion of children, patients with minor complaints not related to liver disease had a somewhat lower infection rate with HAV, HBV and $\mathrm{HCV}$ than the control patients, including the prevalence of $\mathrm{HBs} A \mathrm{~g}$ and anti-HBs.

The prevalence rate of anti-HIV-1 among both controls and liver disease patients was low, averaging $2 \%$.

\section{Immunological markers}

The results are summarized in Tables 4 and 5. Procollagen III was elevated in approximately $75 \%$ of young people, $63 \%$ of blood donors and $53 \%$ of liver disease patients. CA50 antigen was elevated in more liver disease patients than in blood donors, but was also present in $38 \%$ of children up to 5 years old. Anti-nuclear antibodies (ANA) were found in $75 \%$ of liver patients but also in $25-35 \%$ of controls and youngsters. In 13 liver disease patients the titres were $>1: 320$. AMA and AM2 were found in $22 \%$ of liver patients, the corresponding figures for blood donors being $5 \%$ and $16 \%$ respectively. In none of these patients with ANA or AMA could a 
Table 4. Prevalence of immunological markers in patients with minor complaints, not related to liver disease in different age groups

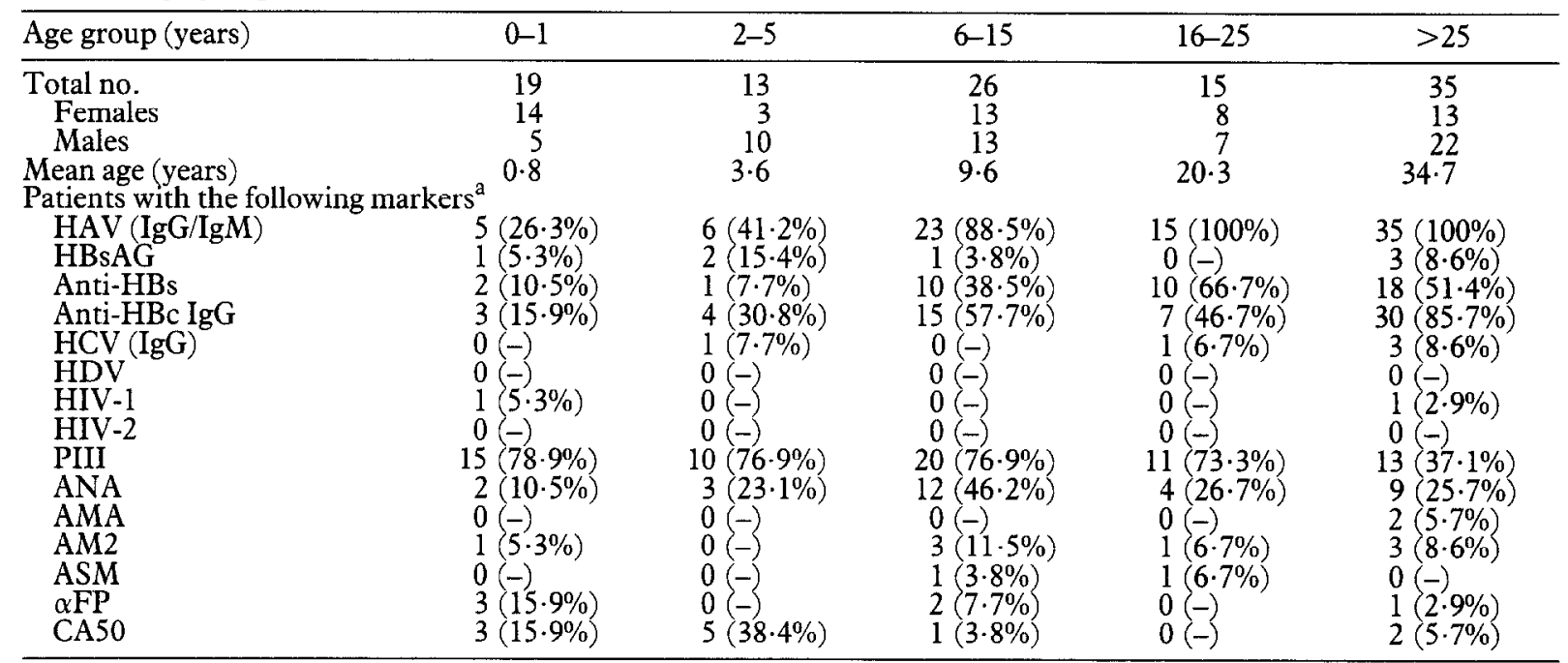

aAMA, anti-mitochondrial antibodies $>1: 10 ; \mathrm{AM} 2$, anti-M2, antibodies $>10$ units $/ \mathrm{mL}$; ANA, antinuclear antibodies $>1: 10$; ASM, anti-smooth muscle antibodies $>1: 10$; CA50, monoclonal anti-CA50 antigen (RIA-gnost ${ }^{\circledR}$, Behring, Mannheim, Germany) >normal level; $\alpha \mathrm{FP}, \alpha$-foetoprotein $>$ normal level; PIII, procollagen III peptides $>$ normal level.

Table 5. Prevalence of immunological markers in patients with liver disease and in healthy blood donors

\begin{tabular}{lcc}
\hline Markers $^{2}$ & $\begin{array}{c}\text { Patients with } \\
\text { liver disease }\end{array}$ & Blood donors \\
\hline PIII & $45 / 84(53 \cdot 5 \%)$ & $51 / 81(63 \cdot 0 \%)$ \\
CA50 & $72 / 84(85 \cdot 7 \%)$ & $3 / 84(3 \cdot 5 \%)$ \\
$\alpha$-Foetoprotein & $22 / 84(26 \cdot 2 \%)$ & $3 / 81(3 \cdot 7 \%)$ \\
ANA & $63 / 84(75 \cdot 0 \%)$ & $24 / 65(36.9 \%)$ \\
AMA & $19 / 84(22 \cdot 6 \%)$ & $3 / 65(4 \cdot 6 \%)$ \\
AM2 & $19 / 84(22 \cdot 6 \%)$ & $8 / 50(16.0 \%)$ \\
ASM & $6 / 84(7 \cdot 1 \%)$ & $1 / 65(1 \cdot 5 \%)$ \\
\hline
\end{tabular}

aFor explanation, see footnote to Table 4.

Table 6. Correlation between hepatocellular carcinoma and antihepatitis $\mathrm{C}$ antibody or hepatitis $\mathrm{B}$ surface antigen

\begin{tabular}{cccccc}
\hline & \multicolumn{3}{c}{ Anti-hepatitis $\mathrm{C}^{\mathrm{b}}$} & \multicolumn{2}{c}{ Hepatitis B surface } \\
& Total & Present & Absent & Present & Absent \\
\hline Hepatocellular carcinoma & ${ }^{\mathrm{a}}$ & & & \\
Present & 14 & $4(28 \cdot 6 \%)$ & $10(71 \cdot 4 \%)$ & $9(64-3 \%)$ & $5(35 \cdot 7 \%)$ \\
Absent & 62 & 11 & 51 & 13 & 49 \\
Total & 76 & 15 & 61 & 22 & 54 \\
\hline
\end{tabular}

${ }^{a}$ All patients with carcinoma had at least one marker of hepatitis $B$ virus infection.

Correlation between carcinoma and anti-hepatitis $\mathrm{C}: \gamma^{2}=0.8455, P=0.36$ ${ }^{c}$ Correlation between carcinoma and hepatitis $\mathrm{B}$ surface antigen $\chi^{2}=10 \cdot 42, P=0.0012$.

clinical or histological correlation with an autoimmune liver disease be found. $\alpha$-Foctoprotein was significantly commoner in liver disease patients and children up to 5 years old than in controls.

\section{Cirrhosis}

HBsAg was present in $47 \%$ of paticnts with cirrhosis, somewhat fewer than patients with HCC. Liver cirrhosis Table 7. Correlation between liver cirrhosis and hepatitis $\mathrm{C}$ virus or hepatitis B surface antigen

\begin{tabular}{lccccc}
\hline & & \multicolumn{2}{c}{ Hepatitis C virus } & \multicolumn{2}{c}{ Hepatitis B surface } \\
antigen & Absent \\
& Total & Present & Absent & Present & Absent \\
\hline Cirrhosis & 19 & $8(53 \%)$ & $11(18 \%)$ & $9(41 \%)$ & $10(19 \%)$ \\
Present & 19 & $7(47 \%)$ & $50(82 \%)$ & $13(59 \%)$ & $44(81 \%)$ \\
Absent & 57 & 15 & 61 & 22 & 54 \\
Total & 76 & & & & \\
\hline
\end{tabular}

was associated in $42 \%$ with anti-HCV, indicating a combined infection with HBV and HCV (Table 7).

Cirrhosis of the liver was correlated with both $\mathrm{HCV}$ infection $\left(\chi^{2}=8.0 ; P=0.0047\right)$ and the presence of HBsAg $\left(\chi^{2}=4 \cdot 18 ; P=0 \cdot 041\right)$.

All patients with liver cirrhosis, HCC, and chronic active or persistent hepatitis had at least one serum marker of $\mathrm{HBV}$ infection, and $53 \%(10)$ of the patients with liver cirrhosis had evidence of a combined infection with HBV and $\mathrm{HCV}$, while $42 \%$ (8) of them were $\mathrm{HBsAG}$ negative.

Five patients with HCC (38\%) showed evidence of combined infection with $\mathrm{HBV}$ and $\mathrm{HCV}$, and 5 had markers of HBV infection only.

Of the 7 patients with chronic active and the 3 with persistent hepatitis, 4 and 1, respectively, had markers of both $\mathrm{HBV}$ and $\mathrm{HCV}$ infection, while 3 and 2 , respectively, had markers of HBV infection only.

\section{Discussion}

Although HAV and IIBV had infected virtually every adult and a substantial number of the juvenile persons in our study, about one-third of the patients with liver disease were also affected by some other hepatic disease (Table 1).

Ultrasound proved to be particularly useful in the visualization of focal hepatic lesions, although differentiation between amoebic liver abscess, HCC or malignant lymphoma can be very difficult (MISSALEK, 1992). Immediate puncture and aspiration can enable a rapid diagnosis. Thus abdominal ultrasound is an efficient screening diagnostic tool, while laparoscopy is even more helpful in making a definite diagnosis, confirmed by histology.

Clinical signs of chronic liver disease, common among Caucasians, such as spider naevi, palmar erythema, loss of abdominal hair, and testicular atrophy are rarely seen in Black Africans (LEEVy et al., 1977). Variceal haemorrhage, severe disorders of coagulation and portosystemic encephalopathy were not observed in this survey. Elevation of $\gamma$-glutamyltransferase in serum was the most frequently abnormal liver function test. Nevertheless, its sensitivity of only $67 \%$ among liver disease patients is too low for screening purposes. Bleeding and coagulation time proved also to be of little help in evaluating diffuse parenchymatous liver disease.

Although a substantial number of $\mathrm{HBV}$ infections probably occurs in the perinatal period, anti-HBc posi- 
tivity steadily increases in the first 15 years of life (WHO 1991). The source of infection during this period is not clear. Horizontal spread among small children, skin piercing as a traditional treatment or custom (scarification, circumcision), and early sexual activity may all play a role (NDUMBE, 1992; KAO et al., 1993; NDUMBE \& SKALSKY, 1993).

The HCV infection rate was comparatively low in the control population, especially in childhood, the time at which most blood transfusions are given for severe, malaria-associated anaemia. Concomitant $\mathrm{HCV}$ infection was, however, present in $18 \%$ of our patients with liver disease. There was some evidence that the prevalence of anti-HCV antibodies increased with age: 3 of 35 subjects aged over 25 years had anti-HCV $\operatorname{IgG}$, compared with 2 of 73 of those aged 25 years or less (Table 4). This is in agreement with the marked prevalence of anti-HCV in persons over 40 years of age reported in a recent survey of another rural forest area in Cameroon (LouIs et al., 1994).

Given the high rate of $\mathrm{HBV}$ infection in controls and the three-fold increases in prevalence of HCV infection in liver disease patients (a seven-fold increase in cirrhosis) compared to controls, it may be speculated that $\mathrm{HCV}$ infection is of considerable importance in the development of chronic liver pathology. The mode of infection with $\mathrm{HCV}$ in our population is uncertain. Blood transfusions do not seem to play a major role.

There was a significant positive correlation between liver cirrhosis, $\mathrm{HCC}$ and $\mathrm{HBsAg}$, and between liver cirrhosis and anti-HCV, but only a weak positive correlation between HCV infection and HCC.

A high frequency of positive autoantibodies, especially ANA (speckled pattern), has been described previously in regions endemic for falciparum malaria (BOONPUCKNAVIG \& EKAPANYAKUL, 1984; see also ACETI et al., 1990). The autoantibodies, however, might also be markers of an autoimmune process, triggered by a previous hepatitis virus infection (LENZI et al., 1991; VENTO et al., 1991). Histologically and clinically, however, we found neither chronic autoimmune hepatitis nor primary biliary cirrhosis in our survey, despite the rather high prevalence of ANA and AM2 autoantibodies among liver disease patients.

The prevalence of a positive rapid plasma reagin test (RPR) for syphilis (17\%) and the HCV prevalence of $6 \%$ in pregnant women (Table 3 ) were relatively high. Similar results have been reported from the adult population of Yaoundć, the capital of Camcroon, where the sera were tested by Treponema pallidum haemagglutination (TPHA), a more specific antibody test for syphilis (NDUMBE, 1992), and for hepatitis C antibodies (MENCARINI, 1991)

Whether there is a relationship between genital ulcer disease and HCV transmission, as there is for HIV-1 transmission, needs further investigation. This was suggested by further observations from Yaoundé, where the seroprevalence of $\mathrm{HCV}$ antibodies among prostitutes was about twice that of pregnant women (NDUMBE \& SKAL SKY, 1993) and by the fact that, in our cohort, the seroprevalence of $\mathrm{HCV}$ antibodies among pregnant women with a positive RPR was about twice that observed in
RPR negative pregnant women.

Positive HIV-1 status seemed not to have an influence on the cxpression of the different anti-hepatitis antibodies, especially $\mathrm{HBsAg}$ and anti-HCV, in our study.

As HBV and HCV seem to play an important role in chronic liver disease in the area we investigated, the prevalence of $\mathrm{HBsAg}(5.4 \%)$ and anti-HCV antibodies $(6.1 \%)$ in pregnant women, with the risk of vertical transmission (THALER et al., 1992), is of epidemiological importance and supports the introduction of early vaccination against $\mathrm{HBV}$ and, in the future, if available, $\mathrm{HCV}$ in the Expanded Programme on Immunization (WHO, 1991; NDUMBE \& YENSHU, 1992).

\section{References}

Aceti, A., Taliani, G., Bac, C. \& Sebastiani, A. (1990). AntiHCV false positivity in malaria. Lancet, 336, 1442-1443.

Boonpucknavig, S. \& Ekapanyakul, G. (1984). Autoantibodies in sera of Thai patients with Plasmodium falciparum infection. Clinical Immunology, 58, 77-82.

Kao, J. H., Chen, P. J., Ming, Y. L., Teh-Hong Wang \& Ding-Shiun Chen (1993). Sexual transmission of HCV. Lancet, 342,622 .

Leevy, C. M., Popper, H. \& Sherlock, S. (1977). Diseases of the Liver and Biliary Tract. Standardization of Nomenclature; Diagnostic Methodology. Chicago: Yearbook Medical Publishers.

Lenzi, M., Johnson, P. J. \& McFarlane, I. G. (1991). Antibodies to hepatitis $\mathrm{C}$ virus in autoimmune liver disease; evidence of geographical heterogeneity. Lancet, 338, 277-280.

Louis, F. J., Maubert, B., Le Hesran, J.-Y., Kemmegne, J., Delaporte, E. \& Louis, J.-P. (1994). High prevalence of antihepatitis $C$ virus antibodies in a Cameroon rural forest area. Transactions of the Royal Society of Tropical Medicine and Hygiene, 88, 53-54.

Mencarini, P., De Luca, A., Antinori, A., Maiuro, G., Spedini, G., Bailly, C. \& Tamburrini, E. (1991). Prevalence of antiHCV antibodies in Cameroon. Transactions of the Royal Society of Tropical Medicine and Hygiene, 85, 654-655.

Missalek, W. (1992). Ultrasonography in the diagnosis of amoebic liver abscess and its complications. Tropical Doctor, $22,59-64$

Ndumbe, P. M. (1992). Sexually transmitted infections in selected high risk populations in Cameroon. Genitourinary $\mathrm{Me}$ dicine, 68, 193-194.

Ndumbe, P. M. \& Skalsky, J. A. (1993). Hepatitis C virus infection in different populations in Cameroon. Scandinavian foumal of Infectious Diseases, 25, 689-692.

Ndumbe, P. M. \& Yenshu, E. (1992). Vaccination and politics. Lancet, 339, 1222 .

Thaler, M. M., Choong-Kee Park, Landers, D. V., Wara, D W. Houghton, M. Veereman-Wauters, G., Sweet, R. L. \& Han, J. H. (1992). Vertical transmission of hepatitis C virus. Lancet, 338, 754-757.

Vento, S., Garofano, T. \& Di Perri, G. (1991). Identification of hepatitis $A$ virus as a trigger for autoimmune chronic hepatitis type 1 in susceptible individuals. Lancet, 337, 1183-1187.

WHO (1980). Manual of Basic Techniques for a Health Laboratory. Geneva: World Health Organization.

WHO (1991). Towards the elimination of hepatitis B: a guide to the implementation of national immunization programs in the developing world. Document issued by the Conference on the Control of Hepatitis $B$ in the Developing World, Y'aoundé, October 7-11, 1991. Geneva: World Health Organization.

Received 9 November 1994; revised 6 February 1995; accepted for publication 9 February 1995 